\title{
Effect of Multiwalled Carbon Nanotubes on Improvement of Fracture Toughness of Spark-Plasma-Sintered Yttria-Stabilized Zirconia Nanocomposites
}

\author{
T. Arunkumar, G. Anand, Ram Subbiah, R. Karthikeyan, and Jaya Jeevahan
}

\author{
Submitted: 10 October 2020 / Revised: 29 January 2021 / Accepted: 2 February 2021 / Published online: 22 February 2021
}

\begin{abstract}
Highly dense yttria-stabilized zirconia (YSZ) nano-ceramics reinforced with TC-CVD-synthesized multiwall carbon nanotubes (MWCNTs) were fabricated using spark plasma sintering at a temperature of $1350^{\circ} \mathrm{C}$, the heating rate of $100{ }^{\circ} \mathrm{C} / \mathrm{min}$ and pressure of $50 \mathrm{MPa}$ with a dwell time of 10 minutes. The identical parameters were utilized for fabricating composites with a varying weight ratio of YSZ and MWNCTs. The samples were characterized for their phase transformation, microstructure and elemental composition using x-ray diffraction (XRD), scanning electron microscopy (SEM) and energy-dispersive spectroscopy (EDS). The physical and mechanical properties such as density, porosity, hardness, fracture toughness and wear were also investigated. The increase in the MWCNTs concentration has resulted in the deterioration of the hardness due to CNT agglomerations. The wear resistance of the composites revealed MWNCTs enhanced wear resistance of YSZ nanocomposite by undergoing MWNCTs pull-out and crack branching mechanisms. Further indentation method and single-beam V-notch beam (SEVNB) methods were utilized to study the effect of MWCNTs on the fracture toughness of the nanocomposites. The fracture toughness of YC1 $\left(6.58 \pm 0.3 \mathrm{MPa} \mathrm{m}^{1 / 2}\right)$ was $21 \%$ higher than the YSZ $\left(5.21 \pm 0.2 \mathrm{MPa} \mathrm{m}^{1 / 2}\right)$ due to the toughening mechanisms attributable to crack deflection, branching and bridging of MWCNTs.
\end{abstract}

Keywords energy dissipating mechanisms, fracture toughness, multiwalled carbon nanotubes (MWCNTs), spark plasma sintering (SPS), yttria-stabilized zirconia (YSZ)

\section{Introduction}

Over the decades, ageing has been a common issue for the human being who involves degenerative issues of human joints, musculoskeletal diseases and dental problems. Along with these issues, the increase in traffic accidents has also increased the need for artificial implants that can be used by humans for a lifetime without any maintenance or failure. Researchers have been trying to find a permanent solution using biomaterials with properties compatible with medical research. Since the 1960s,

This invited article is part of a special topical focus in the Journal of Materials Engineering and Performance on Surface Engineering. The issue was organized by Dr. M.K. Banerjee, Malaviya National Institute of Technology, Jaipur.

T. Arunkumar, Department of Mechanical Engineering, CMR Institute of Technology, Bengaluru, India; G. Anand, Department of Mechanical Engineering, MVJ College of Engineering, Bengaluru, India; Ram Subbiah, Department of Mechanical Engineering, Gokaraju Rangaraju Institute of Engineering and Technology, Hyderabad, India; R. Karthikeyan, Department of Aerospace and Aircraft Engineering, Roehampton Vale Campus, Kingston University London, London SW15 3DW, UK; and Jaya Jeevahan, School of Mechanical Engineering, Sathyabama Institute of Science and Technology, Chennai, India. Contact e-mail: karthikeyan506@gmail.com.
Ti-based alloys have been acting as a prominent biomaterial in orthopaedics such as artificial joints and dental plants due to their higher strength, good corrosion resistance and higher biocompatibility (Ref 1). However, the Ti-based alloys undergo excessive wear which could result in loosening in the implants and have harmful side effects on the human body which include tissue blacking and metallosis. The ions and particles of Titanium alloys are deposited in different parts of tissues leading to toxic reactions that could result in yellow nail syndrome. Furthermore, hypersensitivity reactions can lead to implant failure and allergic reactions (Ref 2). Recently, advanced ceramics and their composites have expanded their applications in various fields such as biomedical, structural and aerospace industries. Among advanced ceramics, YSZ (yttria-stabilized zirconia) has been a keen interest to researchers in the field of biomedical applications such as dental implants, femoral ball head, prosthetic heart valves and ligaments owing to its excellent properties like high fracture toughness, biocompatibility, high wear resistance and low plaque affinity (Ref 3-6). Being a wellstudied ceramic, the excellent properties of YSZ have led its path into thermal/environmental barrier coatings in aerospace industries and composites in biomedical and structural areas (Ref 710). The YSZ-based biomaterials could have a predominant advantage over the Ti alloys as the material does not pose issues of corrosion or leaching and does not cause the metal allergic patients (Ref 11). However, ageing poses vulnerability toward the reduction in fracture toughness and complete failure of YSZ composites implants in humid environments (Ref 12, 13). Many researchers have investigated the ageing resistance of YSZ by modifying process conditions, confining phase and microstructural transformations and by grain size controlling (Ref 14, 15). To circumvent this problem, materials like $\mathrm{SiC}$ and $\mathrm{Al}_{2} \mathrm{O}_{3}$ were added as composites and a material like $\mathrm{Y}_{2} \mathrm{O}_{3}$ was coated but these changes resulted in a minimal increase in fracture 
toughness (Ref 16, 17). A high ductile material like CNTs which has been the core of research from its discovery by Iijima owing to its excellent mechanical, thermo-chemical stability and biocompatibility could act as reinforcement for YSZ for biomedical (Ref 18-20). The CNT has been used as a strengthening aid in composites and coating along with material to improve their properties. Mehdi et al. studied the effect of 10 vol.\% CNT onto the $\mathrm{ZrB}_{2}$ and concluded that the CNT was responsible for improved fracture toughness of the composites (Ref 21). Likewise, Chen et al. also noted an improvement in tensile and fracture toughness on spark-plasma-sintered $\mathrm{TiB}_{2} /$ CNT composites where the presence of additional CNTs could have led to toughening mechanisms such as crack deflection and bridging (Ref 22). Whereas Oleksii et al. investigated the hotpressed composites of $\mathrm{TiB}_{2} / \mathrm{CNT}$ and concluded that the fracture toughness was not improved whereas the hardness of the samples reduced drastically (Ref 23). The addition of CNT into TiN composites fabricated using spark plasma sintering led to reduced density in the composites with finer microstructure (Ref 24). In most cases, the use of MWCNTs has resulted in the control of composite grain coarsening by binding the grains together leading to increased mechanical properties. However, many researchers stated that the addition of CNT to YSZ could result in a decrease or minimal increase in fracture toughness depending on the percentage of CNT employed. Duszov et al. and Sun et al. reported that the reinforcing CNT with YSZ did not lead to an increase in fracture toughness whereas Garmendia et al, Mazaheri et al, Kasperski et al and Melk et al reported a slight increase in fracture toughness (Ref 25-29). The contradiction in the results may have been due to (i) Increased MWCNTs content may reduce the interfacial bonding between composites resulting in high porosity (ii) Improper sintering methods/temperature/pressure could damage the material causing non-homogenization, agglomeration and impaired/degraded CNT with YSZ (iii) Improper testing methods like indentation fracture toughness cause inconsistency in toughness values (iv) Unsuitable ultrasonication medium and/or pre-treatment may cause inhomogeneous dispersion and impurity of CNT. Therefore, the need for further research to focus on a comprehensive investigation into the effects of MWCNTs on YSZ and resolve the above-mentioned inadequacies. In recent times, spark plasma sintering (SPS) is used for composite preparations due to the rapid sintering process, high densification and minimal material damage, etc (Ref 30-33).

Altogether, the reinforcement of CNT with different material led to increase or decrease in mechanical properties as investigated in numerous studies, but there is no systematic study on the precise quantity of MWCNTs which could simulate the mechanical properties of the material. Also, several controversial fracture toughness values have reported earlier due to various parameter as mentioned above. Therefore, the purpose of this work is to comprehensive study of MWCNT-reinforced YSZ composite prepared by spark plasma sintering method and accomplishes the contentious fracture toughness values.

\section{Materials and Methods}

MWCNTs were used as reinforcement material with 8 YSZ for the fabrication of ceramic matrix composite. In previous work, MWCNTs were synthesized using thermo-catalytic chemical vapor deposition (TC-CVD) with an outer diameter ranging from 20 to $30 \mathrm{~nm}$ and purity greater than $97 \%$ (Ref 34). The commercial $50 \mathrm{~nm}$ YSZ (99\% purity, MK industries, Canada) was used as the raw material for the fabrication of composite using spark plasma sintering process (Ref 35). Ceramic matrix composite was fabricated with different percentages of MWCNTs $(0.5 \sim 5$ wt. $\%)$. The nanocomposites of different compositions (as shown in Table 1) were fabricated by dispersing the MWCNTs into a mixture of ethanol and water in a ratio of $3: 2$ with a 0.5 wt.\% sodium hexametaphosphate as dispenser agent and ultrasonicated using a probe-ultrasonicator (OSCAR, PR600MP) with a frequency of $50 \mathrm{KHz}$ for 20 minutes. Then the YSZ powder was added and stirred vigorously using a magnetic stirrer for uniform blending between YSZ and MWCNTs. Subsequently, the obtained slurry was balled milled (SPEX 8000D, Ukraine) at a constant speed of 300rpm for 5 hours in presence of 12 tungsten carbide balls and further dried using a rotary evaporator (Buchi India Pvt Ltd, India) at a temperature of $100{ }^{\circ} \mathrm{C}$ for 12 hours. The attained powder was sintered using a spark plasma sintering process with graphite die of $20 \mathrm{~mm}$ diameter lined with graphite foil and press. The sintering was performed at a temperature of $1350{ }^{\circ} \mathrm{C}$ with a heating rate of $100{ }^{\circ} \mathrm{C} / \mathrm{min}$ and pressure of 50 $\mathrm{MPa}$ and dwell time of 10 minutes (Ref 36).

The phase composition of the sintered composites was studied using an x-ray diffractometer (smart lab-RIGAKU, Japan). The XRD was carried out at room temperature with $2 \theta$ value ranging from 0 to $90^{\circ}$ and wavelength of $1.54056 \AA$ with a step of $0.05^{\circ} \mathrm{s}^{-1}$ and operational target voltage and tube current of $30 \mathrm{KV}$ and $100 \mathrm{~mA}$ (Ref 37, 38). Surface topographies of the samples were obtained using a scanning electron microscope method (ZEISS SUPRA 55), and simultaneously quantitative elemental analysis was conducted (ASTM D4541) (Ref 39). The EDAX analysis was made at different spots on the samples to ensure the homogenous distribution of MWCNTs. The density of the samples was measured using Archimedes liquid displacement method with water as the immersion medium. Apparent density is the product of water density and ratio between dry sample weight and a difference in weights of dry sample and soaked immersed sample. Likewise, bulk density is the product of water density and ratio between dry sample weight and a difference in weights of soaked sample and soaked immersed sample. Those samples with high porosity were immersed into a mixture of water and lubricant for at least 3 days to ensure filling up of the pores. Then apparent porosity in percentage is the ratio of the difference in weights of soaked and dry samples to a difference in weights of soaked and soaked immersed samples (Ref 40). The Vickers hardness test (Krystal Elmec, India) was conducted as per ASTM C1327 standards with sample dimensions of $4 \mathrm{~mm}$ thickness, $30 \mathrm{~mm}$ diameter and $1 \mu \mathrm{m}$ surface finish. Further, the diamond indenter is used to make an impact on the sample with a load of $10 \mathrm{~N}$ and a dwell time of 20 seconds. The diagonal lengths of the indentation were measured using scanning electron microscopy for further utilization in the calculation of fracture toughness as per Evans and Charles equation (1) where ' $a$ ' is average half-length of the diagonal, ' $c$ ' is the average halfcrack length from the diagonal and $\mathrm{H}_{\mathrm{v}}$ represents Vickers hardness.

Fracturetoughness (Indentation) $K_{I C}$
$=0.203 H_{V} \times a^{\left(\frac{1}{2}\right)} \times\left\{\frac{c}{a}\right\}^{-\left(\frac{3}{2}\right)}$ 
Table 1 Composition of samples

\begin{tabular}{lcccrr}
\hline Sample & YSZ, \% & YC0.5, \% & YC1, \% & YC2, \% & YC5, \% \\
\hline MWCNT (wt.\%) & 0 & 0.5 & 1 & 2 & 5 \\
8YSZ (wt.\%) & 100 & 99.5 & 99 & 98 & 95 \\
\hline
\end{tabular}

Likewise, the single edge v-notch beam method (SEVNB method) was utilized to evaluate the fracture toughness of the composites. The required notch was machined using a diamond saw and tapered with help of a razor blade with $3 \mu \mathrm{m}$ diamond paste. The ASTM C1421 standard is followed for the SEVNB method with a dimension of test specimens being $40 \times 3 \times 4$ $\mathrm{mm}$. The SEVNB test was conducted in a four-point bending system with inner $\left(\mathrm{S}_{2}\right)$ and outer $\left(\mathrm{S}_{1}\right)$ span length of $10 \mathrm{~mm}$ and $20 \mathrm{~mm}$, notch depth 'a' of $\sim 0.5 \mathrm{~mm}$, 'W' and 'B' are width and thickness of specimens, ' $\mathrm{F}$ ' being fracture load obtained through computerized method and $\alpha$ being ratio of notch depth to width of specimens $(\alpha=a / W)$ and ' $Y$ ' being stress intensity factor which was calculated through equation (2). With ' $Y$ ', the fracture toughness of specimens was calculated using equation (3) $(\operatorname{Ref} 41)$

$Y=1.9887-1.326 \alpha-\frac{\left(3.49-0.68 \alpha+1.35 \alpha^{2}\right) \alpha(1-\alpha)}{(1+\alpha)^{2}}$

Fracturetoughness $($ SEVNB)

$K_{I C}=\frac{F}{B \sqrt{W}} \times \frac{S_{1}-S_{2}}{W} \times \frac{3 \sqrt{ } \alpha}{2(1-\alpha)^{1.5}} \times Y$

The wear performance of the samples was investigated using a pin on disc tester (DUCOM TR-20LE-PHM-400ASTM G99) (Ref 42, 43) under the ambient room temperature with a constant sliding speed of $0.523 \mathrm{~m} / \mathrm{s}$ with varying load ( 5 $\mathrm{N}$ and $10 \mathrm{~N})$ and sliding distance $(100$ and $400 \mathrm{~m})$. Then the specific wear rate is calculated from the ratio between volume loss and the product of applied load and sliding distance.

\section{Results and Discussion}

\subsection{Density and Porosity}

The apparent and bulk densities of the samples are slightly varying due to the addition of MWCNT as shown in Fig. 1. The apparent density of $\mathrm{YC} 1$ is $6.23 \mathrm{~g} / \mathrm{cm}^{3}$ which is highest and followed by YC 0.5 is $5.92 \mathrm{~g} / \mathrm{cm}^{3}$, YSZ is $5.83 \mathrm{~g} / \mathrm{cm}^{3}, Y C 2$ is $5.38 \mathrm{~g} / \mathrm{cm}^{3}$ and YC5 is $4.41 \mathrm{~g} / \mathrm{cm}^{3}$. It is shown that the apparent density values are slightly increasing with the addition of MWCNT (up to $1 \%$ ) and dropped from thereon, which may have been a result of CNT filling up the voids inside the composite by slipping away during the compaction process while sintering. However, a higher concentration of MWCNTs in the composite could lead to agglomeration that increases the open pores network resulting in density drop (Ref 44). Nisar et al. reported that $\mathrm{CNT}$ forms a continuous network layer on the samples due to agglomeration which leads to a decrease in the Joule heating by providing low resistance during the SPS process (Ref 45). Inversely the bulk density decreases with the

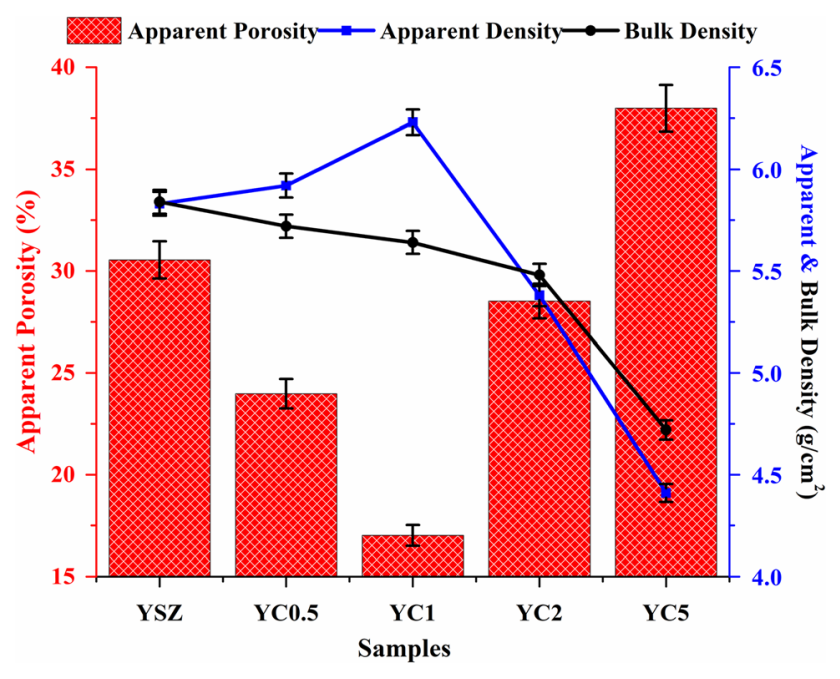

Fig. 1 Apparent and bulk densities along with porosity of the samples

addition of MWCNT. The bulk density of YSZ, YC0.5, YC1, $\mathrm{YC} 2$ and $\mathrm{YC} 5$ are 5.85, 5.72, 5.64, 5.48 and $4.72 \mathrm{~g} / \mathrm{cm}^{3}$, respectively. The extreme decrease in bulk density at a higher amount of MWCNTs may be due to the additional pores volume between and within the particles taken into consideration during its assessment.

Furthermore, the apparent porosity of YC1 is determined to be the lowest compared with other samples. The YC1 acted as the middle range between the porosity values of the composites. Considering the range of porosity, all the five composites could be classified into two categories of closed and open pores (cite 8ysz article). The composites YSZ, YC5 are said to be open pores with porosity values ranging from $30 \%$ or more whereas the other composites YC0.5, YC1 and YC2 is said to be closed pores. By observing the transition from open pores to closed pores between YSZ and YC2, it is evident that the composite which undergoes at high temperature leads to solidstate diffusion of the material which closes up the pores formed on the surface. A study conducted on spark plasma sintering of alumina concluded that the transition of open pores to closed pores occurs at a temperature above $1050^{\circ} \mathrm{C}$ which has been a result of the formation of isolated pores (Ref 46). It is evident that the material undergoes a transition from open to closed pores until an accumulation of $2 \%$ MWCNT, after that the composites again behave as open pores due to the presence of excess MWCNTs which led to weak interfacial bonding forming gaps between the composites resulting in increased porosity. Inversely, when lower amount MWCNT $(<0.5 \%)$ may degrade the carbon content during the sintering process. Thus, fracture propagation at grain boundaries was prevented due to the homogeneous distribution of the precise amount of 
MWCNT ( $\sim 1 \%)$, which act as a barrier and reduced the apparent porosity.

\subsection{Phase Analysis and Surface Morphology}

The phase examination of YSZ mixed with various MWCNT composite powder is shown in Fig. 2. The XRD peaks revealed the presence of tetragonal and cubic phases in all the samples (YSZ \& composites); however, monoclinic phases are present only in composites (YC1, YC2 and YC5) due to a superior amount of MWCNT (ICDD JCPDS 2003 database) (Ref 47). By contrast, a carbon nanotube is unexploited in the YC0.5 sample due to the lower amount of MWCNT decomposed in sintering which is confirmed from elemental analysis (Fig. 5b). Besides, the strongest peak of this phase diagram is a cubic phase appearing at 2 theta of $30.25^{\circ}$. Other peaks of cubic phases were perceived at 2 theta of $35.02^{\circ}$, $62.73^{\circ}$ and $81.95^{\circ}$. Also, tetragonal phases were found at 2 theta of $50.12^{\circ}, 59.91^{\circ}, 74.51^{\circ}$ and $83.5^{\circ}$, respectively. The monoclinic phases of YSZ were perceived only in a higher amount of MWCNT with YSZ (YC1, YC2 and YC5) samples at 2theta of $28.53^{\circ}$. The high intensity was found at YC2 and YC5, and it indicates the high crystallite nature of composites. The present investigation revealed that the phase transition from cubic to tetragonal was found in the YSZ sample, and tetragonal phases were gradually decreased in $\mathrm{YC} 0.5, \mathrm{YC} 1, \mathrm{YC} 2$ and $\mathrm{YC} 5$ samples. The slight monoclinic phases appeared in a higher amount of MWCNT in composites due to the tetragonal phase transition (Ref 48).

Besides, SEM is (Fig. 3) performed on the cross section of polished samples to analyze pores concerning grain size. The surface morphology of YC1 (Fig. 3b) exhibits the close pores, uniform distribution of MWCNT and high interfacial bonding resulting in microstructure refinement. On the other hand, the surface morphology of YC5 (Fig. 3c) shows a deep superficial pore, de-agglomeration of MWCNT and poor interfacial bonding due to a higher amount of MWCNT with YSZ. Furthermore, YSZ, YC0.5 and YC5 samples revealed a coarse structure with an average grain size of $25 \sim 32 \mathrm{~nm}$, which is

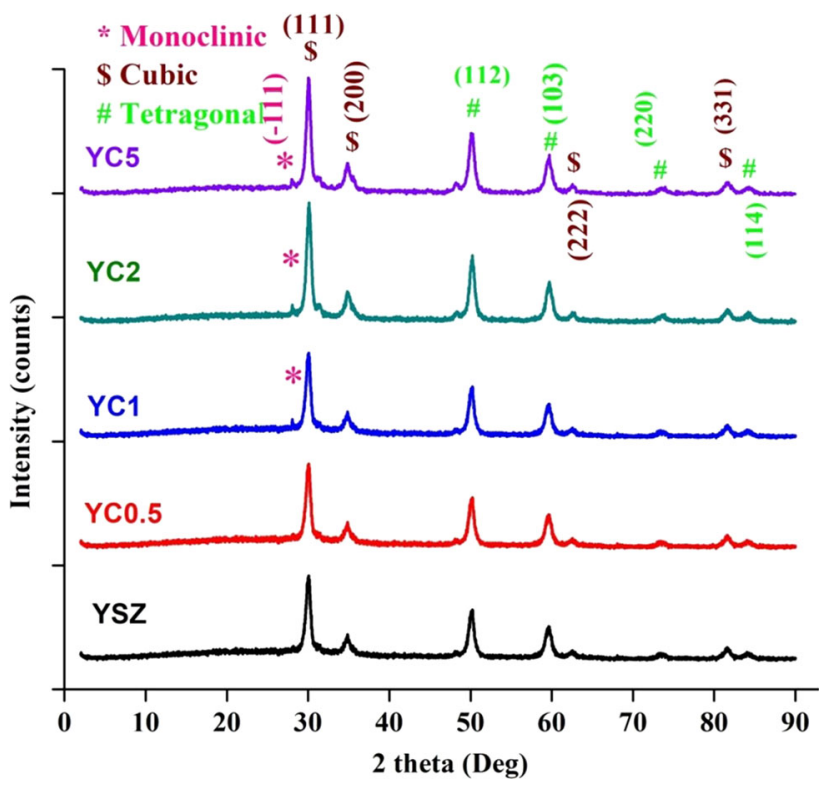

Fig. 2 X-ray diffraction peaks obtained for the specimens sintered at $1350{ }^{\circ} \mathrm{C}$ higher than YC1 and YC2 samples average grain size of $10 \sim 15 \mathrm{~nm}$. However, in Fig. 3(b) sharp grains seem at the edge reflecting well-pinned CNT along grain boundaries. Thus, fracture propagation at grain boundaries was presented and acted as a barrier due to the high aspect ratio and strong Van der Waals' force of attraction among CNTs, also leads the homogeneous distribution (Fig. 4) and reduced the apparent porosity ( $\mathrm{YCl}$ is $17.01 \%$ ). Furthermore, the quantitative elemental values of samples are shown in Fig. 5. Initially, the base material (YSZ) was characterized by quantitative analysis to verify the purity of YSZ. Figure 5(a) confirms the $7.45 \%$ yttria and $92.55 \% \mathrm{ZrO}_{2}$ presence. As expected, the carbon was identified for YC1, YC2 and YC5 (Fig. 5c, d, e) samples and confirmed the MWCNT presence. But in the YC0.5 sample
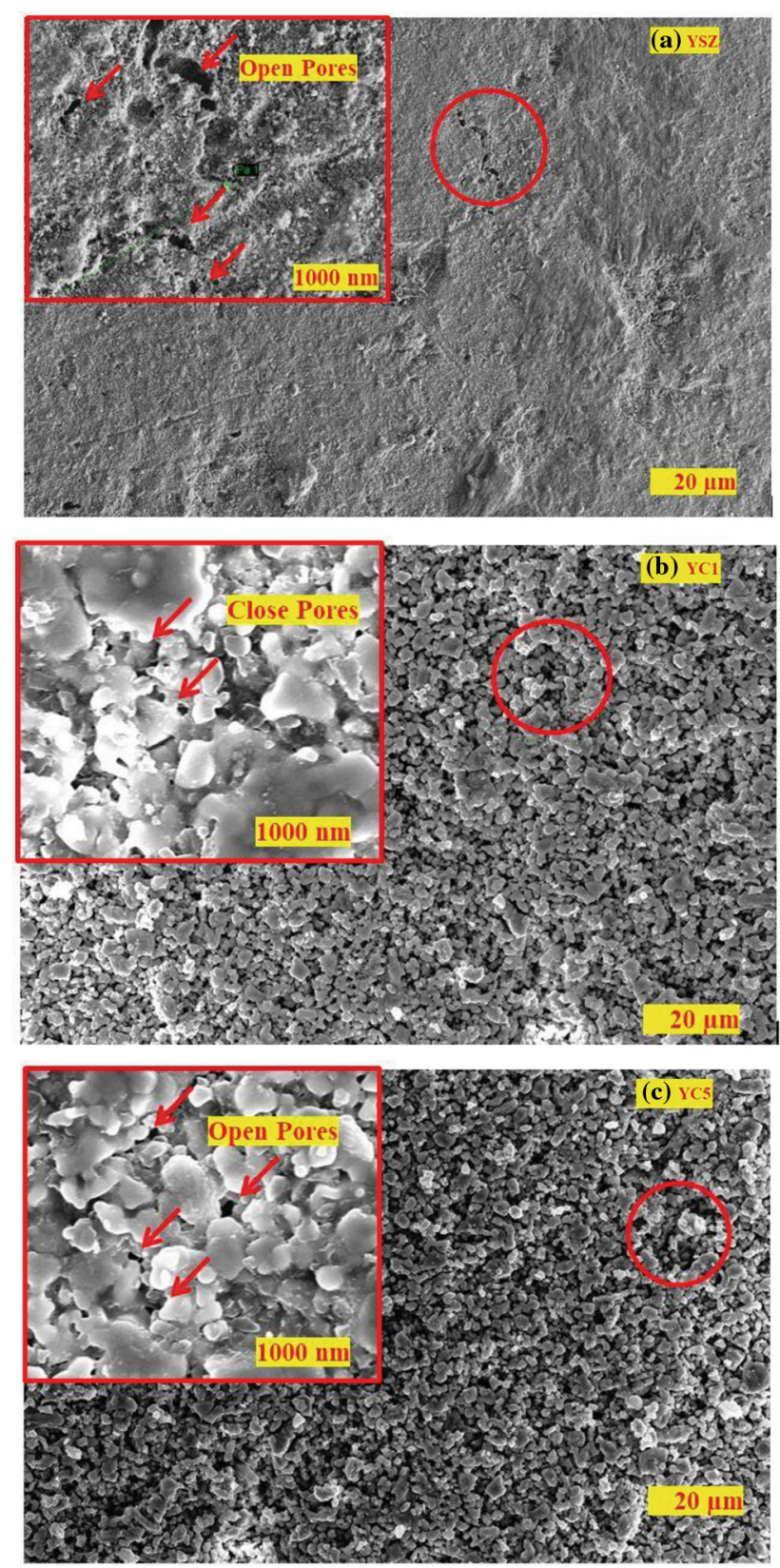

Fig. 3 Scanning electron microscopy image representing (a) open pores of YSZ, (b) closed pores of YC1, (c) open pores of YC5 at same sintering temperature 


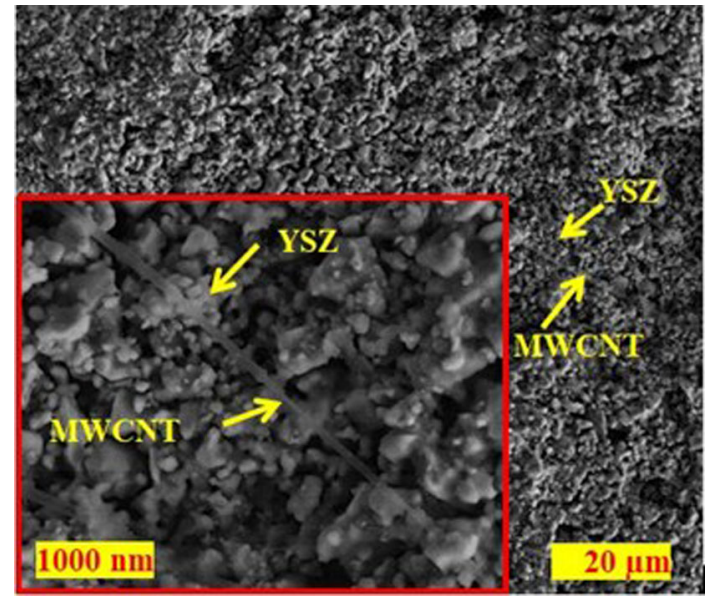

Fig. 4 The entangled CNTs in YC1 sample

(Fig. 5b), carbon content was unexploited which may be due to the decomposition of a lower amount of MWCNT during the sintering process.

\subsection{Mechanical Properties}

Vickers hardness test was carried, out and the diagonal length (Fig. 7a) was calculated from FESEM. The variation of Vickers hardness was uniform and reached a higher value of $13.52 \pm 0.4 \mathrm{GPa}$ for YSZ, $13.58 \pm 0.3 \mathrm{GPa}$ for YC0.5 and $12.96 \pm 0.3 \mathrm{GPa}$ for YC1 (Fig. 6). The high values may have been a result of better suspension of MWCNTs into the matrix and also the grain size reduction by pinning effect of CNTs which inhabits the grain growth. On the other side, hardness of YC2 and YC5 samples decreased successively (10.81 \pm 0.5 and $8.85 \pm 0.7 \mathrm{GPa}$, respectively) due to a higher amount of MWCNT. The Vickers hardness of the nanocomposites shows that the hardness is highly dependent on the CNT content (Ref 49). The increase in MWCNTs contents led to agglomeration and the aggolmated CNTs contained nano pores which were responsible for deterioration in hardness along with weak interfacing bonding between aggolmated CNT and YSZ which is evident from Fig. 3. Nevertheless, the hardness values achieved are higher than the other reported values suggesting that the prolonged ultrasonification of the CNTs led to a homogenous mixture which resulted in increased hardness (Ref $50,51)$.

The indentation fracture toughness (Fig. 6) of YSZ is $5.21 \pm$ $0.2 \mathrm{MPa} \mathrm{m}{ }^{1 / 2}$ which further increases by $\sim 21 \%$ in YC1 $(6.58 \pm$ $\left.0.3 \mathrm{MPa} \mathrm{m}^{1 / 2}\right), 12 \%$ in $\mathrm{YC} 0.5\left(5.93 \pm 0.2 \mathrm{MPa} \mathrm{m}^{1 / 2}\right), 9 \%$ in YC2 $\left(5.78 \pm 0.4 \mathrm{MPa} \mathrm{m}^{1 / 2}\right)$ and then decreases by $4 \%$ in YC5 $\left(4.98 \pm 0.2 \mathrm{MPa} \mathrm{m}^{1 / 2}\right)$. Though, many authors have disputed the reports obtained through the indentation method reporting the method as indirect fracture measurement through cracks propagated (Ref 52). So, another method namely single edge v-notch beam was employed to understand the fracture toughness behavior of the composites. From SEVNB method, the fracture toughness of YSZ is $4.41 \pm 0.4 \mathrm{MPa} \mathrm{m}^{1 / 2}$ which is further increased by $15 \%$ in $\mathrm{YC} 1\left(5.22 \pm 0.3 \mathrm{MPa} \mathrm{m}^{1 / 2}\right), 6 \%$ in YC0.5 $\left(4.72 \pm 0.2 \mathrm{MPa} \mathrm{m}^{1 / 2}\right), 5 \%$ in $\mathrm{YC}^{2}(4.65 \pm 0.2$ $\left.\mathrm{MPa} \mathrm{m}^{1 / 2}\right)$ and then decreases by $9 \%$ in YC5 $(4.01 \pm 0.2$ $\mathrm{MPa} \mathrm{m}^{1 / 2}$ ). Furthermore, the $\mathrm{K}_{\mathrm{IC}}$ values of both the methods are similar trends which are increasing with CNT content after that it has been decreased successively. The precise amount of CNT
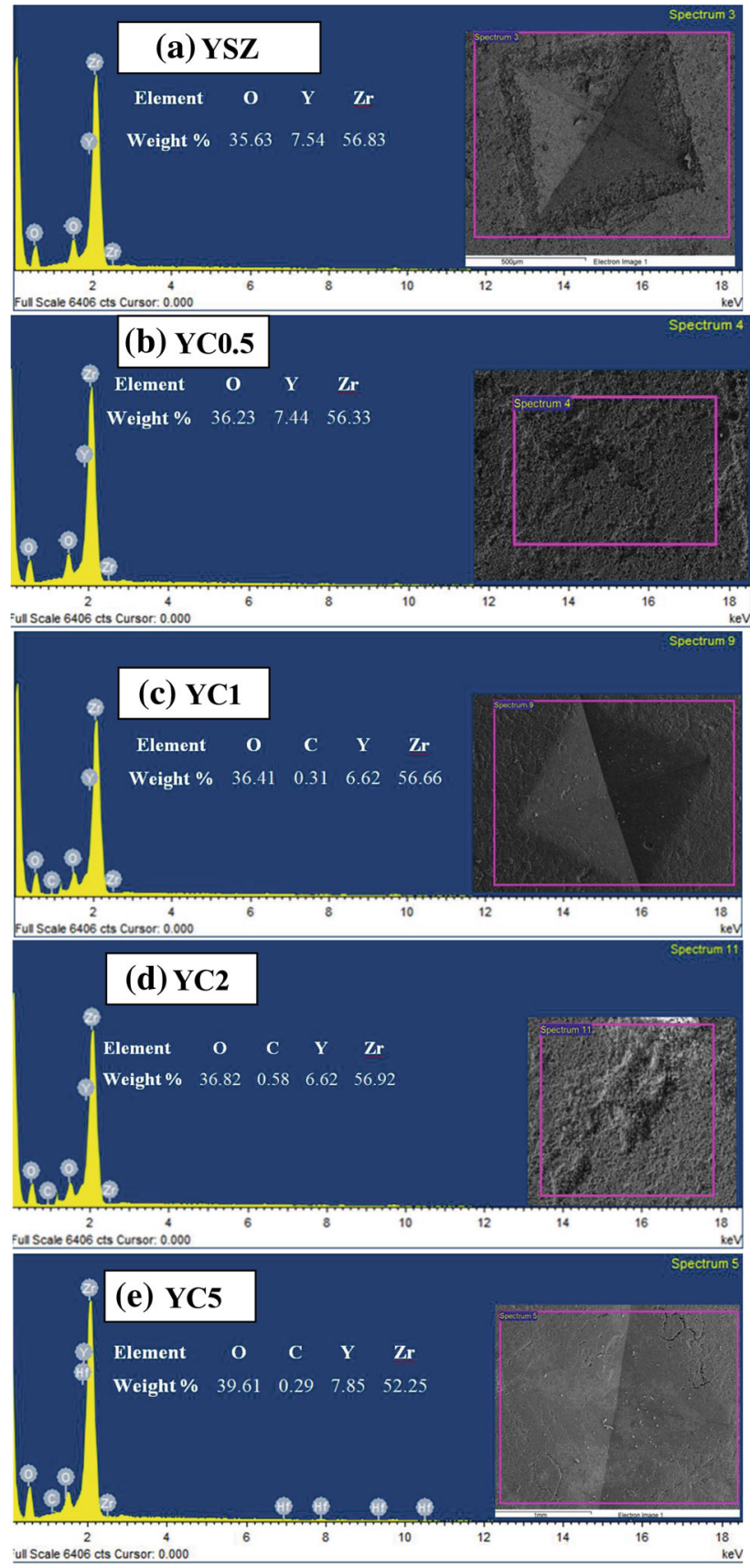

Fig. 5 Quantitative analysis of (a) YSZ, (b) YC0.5, (c) YC1, (d) YC2, (e) YC5 samples

controls the grain growth, well dispersion along grain boundaries which led fracture toughness higher than YSZ in both methods. However, fracture toughness of YC5 is reduced from YSZ due to porosity and weakened interfacial bonding in composite introduced by a higher amount of MWCNT. As reported in the open literature on fiber-reinforced composites undergoes toughening mechanism such as fiber pull-out, crack deflection and crack bridging could also be responsible for enhanced toughness in the composites. Figure 7 shows the fractographic SEM images of cracks formed after the indentation fracture toughness method on the surface of nanocomposites showing crack deflection, bridging and pull-out mechanisms. The propagation of cracks after applied fracture 
load results in uncoiling of the entangled CNTs present in the composites leading to a bridging mechanism. With further propagation of cracks, the uncoiled CNTs stretch by anchoring into one side of the grains of the composites until the ceramic interface. The further cracks propagation in the high porosity

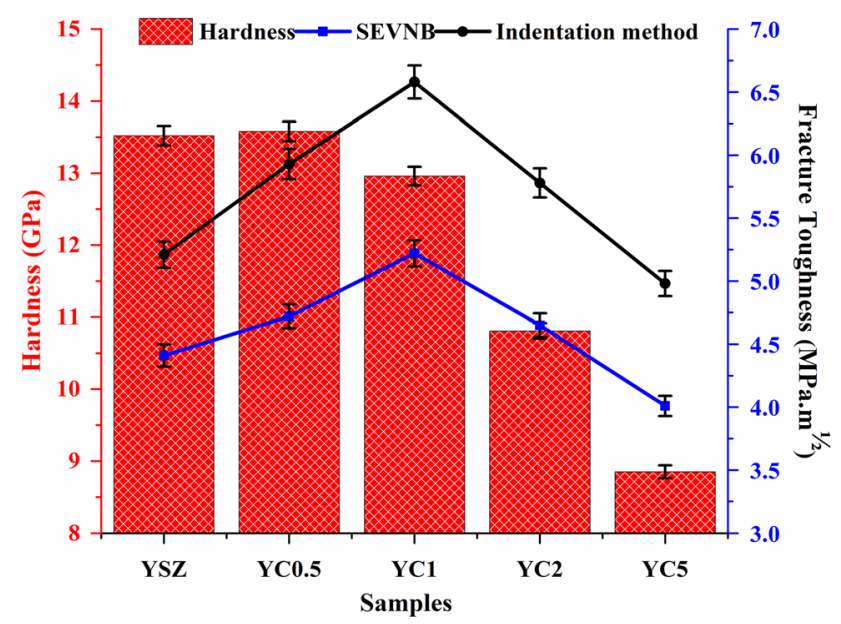

Fig. 6 Hardness and fracture toughness (SEVNB and indentation method) for the samples
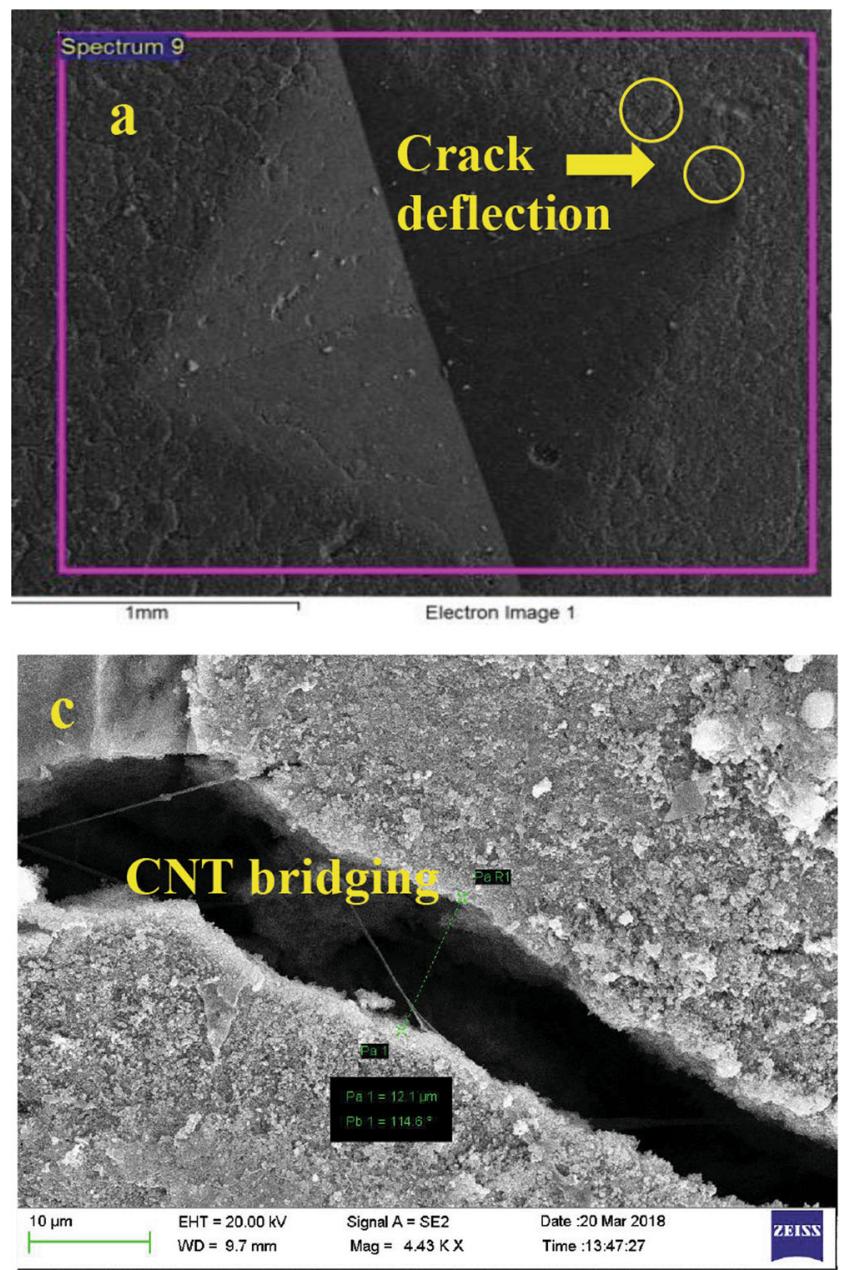

samples leads to failure of CNT stretching resulting in reduced fracture toughness (Ref 53). Figure 7(a) clearly shows that the crack was deflected in multiple directions due to the encircling of YSZ with CNT particles. This crack deflection is consistent with the residual stresses at interfaces due to the difference in thermomechanical properties between YSZ and CNT. These manifold crack deflection in the composite increases energydissipation during crack propagation, leading to increased fracture toughness (Ref 54). Besides, the contribution of crack deflection to raising composite fracture toughening usually depends on the angle of deflection amount. The more twisting crack path is a qualitative sign that more energy was absorbed during crack spreading. The crack bridging and crack branching (Fig. 7b, c, d) mechanisms cause energy dissipation and are related to increased fracture toughness (Ref 55). Overall, experimental values have shown that the indentation fracture toughness values are $\sim 20 \%$ higher than SEVNB method. From these comparisons, it is revealed that the indentation test can be considered only for relative toughness measurement purposes. Hence, it can be concluded that the various controversial $\mathrm{K}_{\mathrm{IC}}$ values reported earlier using the indentation method may be due to parameters chosen like insufficient crack length and grain size values (Ref 56).

The specific wear rates of the samples at a constant sliding speed of $0.523 \mathrm{~m} / \mathrm{s}$, varying applied load $(5$ and $10 \mathrm{~N})$ and varying sliding distance $(100$ and $400 \mathrm{~m})$ are presented in
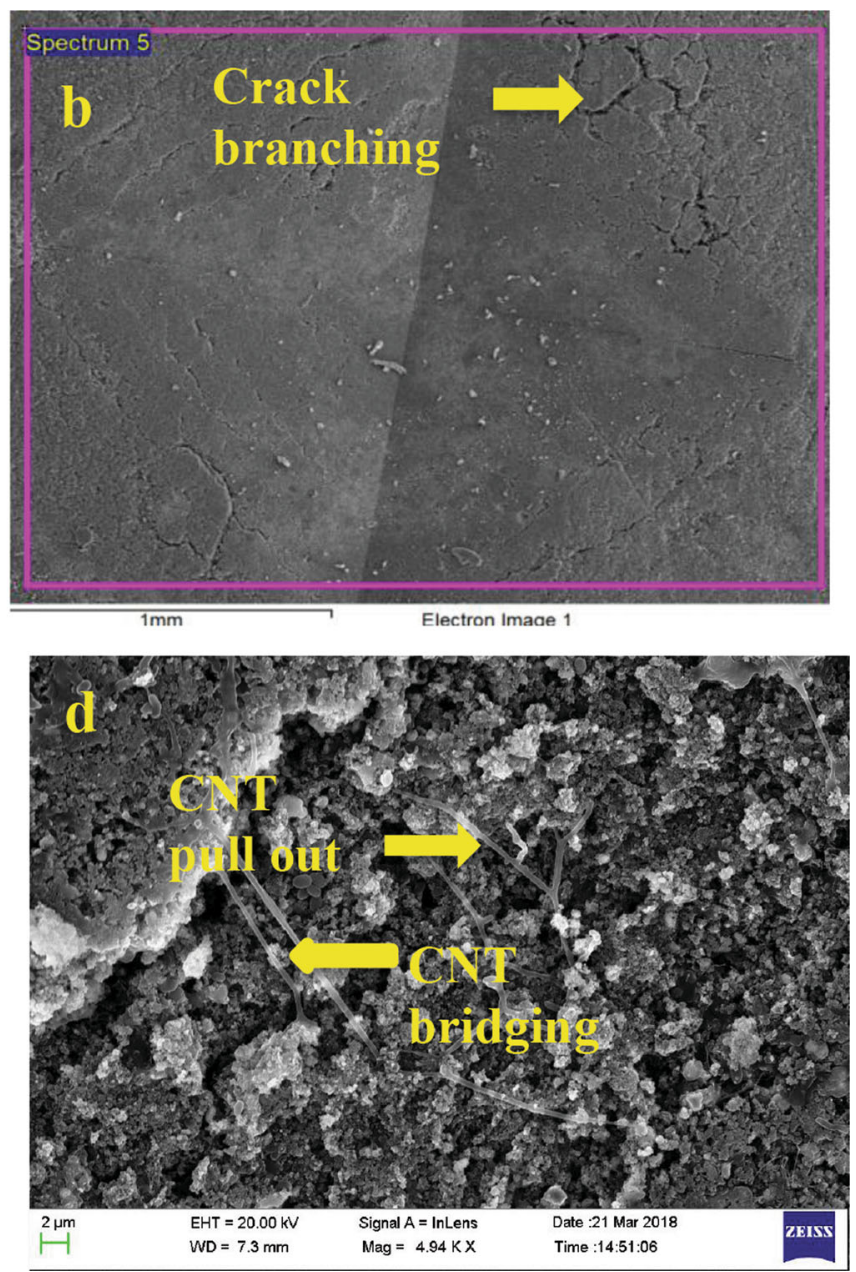

Fig. 7 Fractographic images of crack (a) deflection, (b) branching, (c) bridging and (d) worn surfaces pull out 


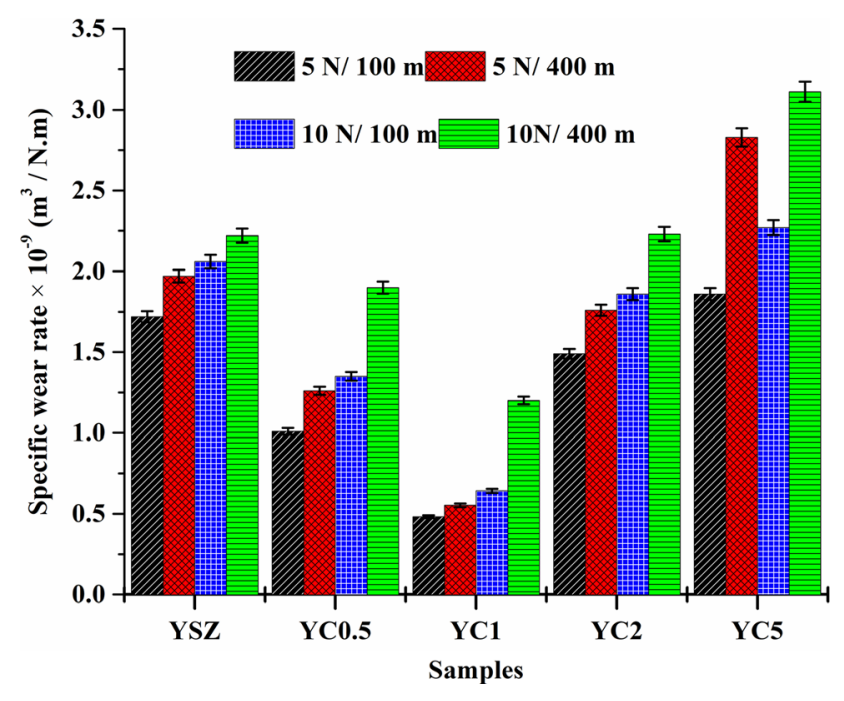

Fig. 8 Specific wear rate of composites

Fig. 8. The wear rate was found to be increased with a load for fixed sliding velocity, but the effect of sliding distance is more pronounced specific wear in all samples (Ref 57). The wear rate of YSZ is $1.72 \times 10^{-9} \mathrm{~m}^{3} / \mathrm{N}$ m $(5 \mathrm{~N} \& 100 \mathrm{~m})$ which further increases their wear resistance by $70 \%$ in $\mathrm{YC} 1\left(0.482 \times 10^{-9}\right.$ $\left.\mathrm{m}^{3} / \mathrm{N} \mathrm{m}\right), 40 \%$ in $\mathrm{YC} 0.5\left(1.01 \times 10^{-9} \mathrm{~m}^{3} / \mathrm{N} \mathrm{m}\right), 13 \%$ in $\mathrm{YC} 2$ $\left(1.49 \times 10^{-9} \mathrm{~m}^{3} / \mathrm{N} \mathrm{m}\right)$ and then decreases by $8 \%$ in YC5 $(1.86$ $\left.\times 10^{-9} \mathrm{~m}^{3} / \mathrm{N} \mathrm{m}\right)$. Likewise, the wear resistance of the remaining samples is increased with loads and sliding distances. However, YC5 samples drastically reduce their wear resistance up to $80 \%$ at a $400 \mathrm{~m}$ sliding distance. The outstanding wear resistance in the $\mathrm{YC} 1$ sample is promising with uniform tribofilm on worn surfaces. On the other side, the YC5 sample has an irregular form and does not protect from a fracture due to de-agglomeration/porosity; in fact, the wear resistance was closely similar (up to $\sim 2 \%$ of MWCNT). However, pull out of MWCNT was found near wear tracks which are acting as an intrinsic lubricant to improve the wear resistance. Therefore, YC1 composite, i.e., precise quantity of MWCNT, has superior wear resistance among all types of samples.

\section{Conclusion}

This contemporary research explored the precise amount of MWCNT with $8 Y$ YSZ on the improvement in structural and mechanical properties. Besides, precise amount of MWCNT controlled the grain growth, well-distributed along grain boundaries and led fracture toughness higher than YSZ in both the methods. The fracture toughness values obtained from indentation are higher (15-20\%) than the SEVNB method. Hence, it can be concluded that the various controversial $\mathrm{K}_{\mathrm{IC}}$ values reported earlier using the indentation method may be due to parameters chosen like insufficient crack length and grain size values. Altogether, this present study revealed that the indentation method is advisable only for relative toughness measurements purpose. Further, the pull out of MWCNT was found near wear tracks act as an intrinsic lubricant to improve the wear resistance. Therefore, MWCNT plays a significant role to influence the wear behavior of composites by energy dissipating mechanisms such as crack-deflection, bridging and branching.

\section{Open Access}

This article is licensed under a Creative Commons Attribution 4.0 International License, which permits use, sharing, adaptation, distribution and reproduction in any medium or format, as long as you give appropriate credit to the original author(s) and the source, provide a link to the Creative Commons licence, and indicate if changes were made. The images or other third party material in this article are included in the article's Creative Commons licence, unless indicated otherwise in a credit line to the material. If material is not included in the article's Creative Commons licence and your intended use is not permitted by statutory regulation or exceeds the permitted use, you will need to obtain permission directly from the copyright holder. To view a copy of this licence, visit http://creativecommons.org/licenses/by/4.0/.

\section{References}

1. M. Kaur and K. Singh, Review on Titanium and Titanium Based Alloys as Biomaterials for Orthopaedic Applications, Mater. Sci. Eng. C, 2019, 102, p 844-862. https://doi.org/10.1016/j.msec.2019.04.064

2. M. Kovochich, B.L. Finley, R. Novick, A.D. Monnot, E. Donovan, K.M. Unice et al., Understanding Outcomes and Toxicological Aspects of Second Generation Metal-on-Metal Hip Implants: A State-of-the-Art Review, Crit. Rev. Toxicol., 2018, 48(10), p 839-887. https://doi.org/ 10.1080/10408444.2018.1563048

3. E. Mohamed, M. Taheri, M. Mehrjoo, M. Mazaheri, A.M. Zahedi, M.A. Shokrgozar et al., In Vitro Biocompatibility and Ageing of 3YTZP/CNTs Composites, Ceram. Int., 2015, 41(10), p 12773-12781. h ttps://doi.org/10.1016/j.ceramint.2015.06.112

4. N. Saito, Y. Usui, K. Aoki, N. Narita, M. Shimizu, K. Hara et al., Carbon Nanotubes: Biomaterial Applications, Chem. Soc. Rev., 2009, 38(7), p 1897. https://doi.org/10.1039/b804822n

5. L.P. Zanello, B. Zhao, H. Hu and R.C. Haddon, Bone Cell Proliferation on Carbon Nanotubes, Nano Lett., 2006, 6(3), p 562-567. https://doi. org/10.1021/n1051861e

6. M. Taheri, M. Mazaheri, F. Golestani-fard, H. Rezaie and R. Schaller, High/Room Temperature Mechanical Properties of 3Y-TZP/CNTs Composites, Ceram. Int., 2014, 40(2), p 3347-3352. https://doi.org/ 10.1016/j.ceramint.2013.09.098

7. S.J. Teh and C.W. Lai, Carbon Nanotubes for Dental Implants, Appl. Nanocompos. Mater. Dent., 2019 https://doi.org/10.1016/b978-0-12-8 13742-0.00005-5

8. J.G. Thakare, C. Pandey, M.M. Mahapatra and R.S. Mulik, Thermal Barrier Coatings-A State of the Art Review, Met. Mater. Int., $2020 \mathrm{~h}$ ttps://doi.org/10.1007/s12540-020-00705-w

9. J.G. Thakare, R.S. Mulik, M.M. Mahapatra and R. Upadhyaya, Hot Corrosion Behavior of Plasma Sprayed 8YSZ-Alumina-CNT Composite Coating in $\mathrm{Na}_{2} \mathrm{SO}_{4}-60 \% \mathrm{~V}_{2} \mathrm{O}_{5}$ Molten Salt Environment, Ceram. Int., 2018, 44(17), p 21533-45. https://doi.org/10.1016/j.cera mint.2018.08.217

10. S. Kanwal, J.G. Thakare, C. Pandey, I. Singh and M.M. Mahapatra, Characterization of Slurry-Based Mullite Coating Deposited on P91 Steel Welds, J. Aust. Ceram. Soc., 2018, 55(2), p 519-528. https://doi. org/10.1007/s41779-018-0258-4

11. J.G. Thakare, R.S. Mulik and M.M. Mahapatra, Effect of Carbon Nanotubes and Aluminum Oxide on the Properties of a Plasma Sprayed Thermal Barrier Coating, Ceram. Int., 2018, 44(1), p 438-451. https:/d oi.org/10.1016/j.ceramint.2017.09.196

12. R. Osman and M. Swain, A Critical Review of Dental Implant Materials with an Emphasis on Titanium versus Zirconia, Materials, 2015, 8(3), p 932-958. https://doi.org/10.3390/ma8030932

13. N. Garmendia, S. Grandjean, J. Chevalier, L.A. Diaz, R. Torrecillas and I. Obieta, Zirconia-Multiwall Carbon Nanotubes Dense Nano-Composites with an Unusual Balance Between Crack and Ageing 
Resistance, J. Eur. Ceram. Soc., 2011, 31(6), p 1009-1014. https://doi. org/10.1016/j.jeurceramsoc.2010.12.029

14. M. Mazaheri, D. Mari, R. Schaller, G. Bonnefont and G. Fantozzi, Processing of Yttria Stabilized Zirconia Reinforced with Multi-walled Carbon Nanotubes with Attractive Mechanical Properties, J. Eur Ceram. Soc., 2011, 31(14), p 2691-2698. https://doi.org/10.1016/j.je urceramsoc.2010.11.009

15. C. Piconi, W. Burger, H.G. Richter, A. Cittadini, G. Maccauro, V. Covacci et al., Y-TZP Ceramics for Artificial Joint Replacements, Biomaterials, 1998, 19(16), p 1489-1494. https://doi.org/10.1016/s01 42-9612(98)00064-7

16. J. Chevalier, What Future for Zirconia as a Biomaterial?, Biomaterials, 2006, 27(4), p 535-543. https://doi.org/10.1016/j.biomaterials.2005.0 7.034

17. A. Samodurova, A. Kocjan, M.V. Swain and T. Kosmač, The Combined Effect of Alumina and Silica Co-Doping on the Ageing Resistance of 3Y-TZP Bioceramics, Acta Biomater, 2015, 11, p $477-$ 487. https://doi.org/10.1016/j.actbio.2014.09.009

18. S. Kun Lee, R. Tandon, M.J. Readey and B.R. Lawn, Scratch Damage in Zirconia Ceramics, J. Am. Ceram. Soc., 2004, 83(6), p 1428-1432. h ttps://doi.org/10.1111/j.1151-2916.2000.tb01406.x

19. M. Mazaheri, D. Mari, Z.R. Hesabi, R. Schaller and G. Fantozzi, Multiwalled Carbon Nanotube/Nanostructured Zirconia Composites: Outstanding Mechanical Properties in a Wide Range of Temperature, Compos. Sci. Technol., 2011, 71(7), p 939-945. https://doi.org/10.10 16/j.compscitech.2011.01.017

20. A. Duszová, J. Dusza, K. Tomášek, G. Blugan and J. Kuebler, Microstructure and Properties of Carbon Nanotube/Zirconia Composite, J. Eur. Ceram. Soc., 2008, 28(5), p 1023-1027. https://doi.org/10. 1016/j.jeurceramsoc.2007.09.011

21. S. Iijima, Carbon Nanotubes: Past, Present, and Future, Physica B, 2002, 323(1-4), p 1-5. https://doi.org/10.1016/s0921-4526(02)008694

22. M. Shahedi Asl, I. Farahbakhsh and B. Nayebi, Characteristics of Multi-walled Carbon Nanotube Toughened $\mathrm{ZrB}_{2}-\mathrm{SiC}$ Ceramic Composite Prepared by Hot Pressing, Ceram. Int., 2016, 42(1), p 19501958. https://doi.org/10.1016/j.ceramint.2015.09.165

23. W. Chen, J. Lin, Y. Yang and H. Zhang, Microstructure and Mechanical Properties of $\mathrm{TiB}_{2}$-CNTs Composites Prepared by Spark Plasma Sintering, Sci. Adv. Mater., 2018, 10(12), p 1782-1787. https://doi.org/ 10.1166/sam.2018.3392

24. O. Popov, J. Vleugels, A. Huseynov and V. Vishnyakov, Reactive Sintering of $\mathrm{TiB}_{2}$-SiC-CNT Ceramics, Ceram. Int., 2019, 45(17), p 22769-22774. https://doi.org/10.1016/j.ceramint.2019.07.317

25. S.A. Delbari, B. Nayebi, E. Ghasali, M. Shokouhimehr and A.M. Shahedi, Spark Plasma Sintering of TiN Ceramics Codoped with $\mathrm{SiC}$ and CNT, Ceram. Int., 2019, 45(3), p 3207-3216. https://doi.org/10. 1016/j.ceramint.2018.10.223

26. J. Sun, L. Gao, M. Iwasa, T. Nakayama and K. Niihara, Failure Investigation of Carbon Nanotube/3Y-TZP Nanocomposites, Ceram. Int., 2005, 31(8), p 1131-1134. https://doi.org/10.1016/j.ceramint.200 4.11.010

27. N. Garmendia, I. Santacruz, R. Moreno and I. Obieta, ZirconiaMWCNT Nanocomposites for Biomedical Applications Obtained by Colloidal Processing, J. Mater. Sci. Mater. Med., 2010, 21(5), p 14451451. https://doi.org/10.1007/s10856-010-4023-7

28. A. Kasperski, A. Weibel, D. Alkattan, C. Estournès, V. Turq, C. Laurent et al., Microhardness and Friction Coefficient of Multi-walled Carbon Nanotube-Yttria-Stabilized $\mathrm{ZrO}_{2}$ Composites Prepared by Spark Plasma Sintering, Scr. Mater., 2013, 69(4), p 338-341. https:// doi.org/10.1016/j.scriptamat.2013.05.015

29. L. Melk, J.J. Roa Rovira, M.-L. Antti and M. Anglada, Coefficient of Friction and Wear Resistance of Zirconia-MWCNTs Composites, Ceram. Int., 2015, 41(1), p 459-468. https://doi.org/10.1016/j.cerami nt.2014.08.092

30. Q. Fu, L. Zhuang, Q. Ren, L. Feng, H. Li and Y. Guo, Carbon Nanotube-Toughened Interlocking Buffer Layer to Improve the Adhesion Strength and Thermal Shock Resistance of SiC Coating for C/C-ZrC-SiC Composites, J. Materiomics, 2015, 1(3), p 245-252. h ttps://doi.org/10.1016/j.jmat.2015.07.006

31. P. Zhao, Q. Li, R. Yi, Z. Wang, L. Lu, X. Cheng et al., Fabrication and Microstructure of Liquid Sintered Porous SiC Ceramics Through Spark Plasma Sintering, J. Alloys Compd., 2018, 748, p 36-43. https://doi. org/10.1016/j.jallcom.2018.03.122
32. N. Saheb and U. Hayat, Electrical Conductivity and Thermal Properties of Spark Plasma Sintered $\mathrm{Al}_{2} \mathrm{O}_{3}$-SiC-CNT Hybrid Nanocomposites, Ceram. Int., 2017, 43(7), p 5715-5722. https://doi.org/10.1016/j.cera mint.2017.01.112

33. S. Dolati, A. Azarniya, A. Azarniya, H. Eslami-shahed, H.R.M. Hosseini and A. Simchi, Toughening Mechanisms of SiC-Bonded CNT Bulk Nanocomposites Prepared by Spark Plasma Sintering, Int. J. Refract Metal Hard Mater, 2018, 71, p 61-69. https://doi.org/10.1016/ j.ijrmhm.2017.10.024

34. T. Arunkumar, R. Karthikeyan, R. Ram Subramani, K. Viswanathan and M. Anish, Synthesis and Characterisation of Multi Walled Carbon Nanotubes (MWCNT), Int. J. Ambient Energy, 2018 https://doi.org/10. 1080/01430750.2018.1472657

35. P. Coquay, E. De Grave, A. Peigney, R.E. Vandenberghe and C. Laurent, Carbon Nanotubes by a CVD Method. Part I: Synthesis and Characterization of the (Mg, Fe)O Catalysts, J. Phys. Chem. B, 2002, 106(51), p 13186-98. https://doi.org/10.1021/jp026631s

36. T. Arunkumar, R. Karthikeyan, R.R. Subramani, M. Anish, J. Theerthagiri, R. Boddula et al., Effect of MWCNTs on Improvement of Fracture Toughness of Spark Plasma Sintered SiC Nano-Composites, Curr. Anal. Chem., 2020 https://doi.org/10.2174/1573411016666 200102120121

37. T. Arunkumar and S. Ramachandran, Investigation of Morphological and Mechanical Features of Polyurea, Appl. Mech. Mater., 2015, 766767, p 606-611. https://doi.org/10.4028/www.scientific.net/amm.766767.606

38. T. Arunkumar and S. Ramachandran, Surface Coating and Characterisation of Polyurea for Liquid Storage, Int. J. Ambient Energy, 2016, 38(8), p 781-787. https://doi.org/10.1080/01430750.2016.1222966

39. T. Arunkumar, S. Sunitha, J. Theerthagiri, J. Jeevagan, M. Anish and T. Tatarchuk, Effect of Polyurea Coating on Corrosion Resistance Over Mild Steel and Aluminium Substrates for Liquid Storage Applications, Mol. Cryst. Liq. Cryst., 2018, 670(1), p 60-73. https://doi.org/10.1080/ 15421406.2018.1542065

40. A. Nisar, S. Ariharan and K. Balani, Establishing MicrostructureMechanical Property Correlation in ZrB2-Based Ultra-High Temperature Ceramic Composites, Ceram. Int., 2017, 43(16), p 13483-13492. https://doi.org/10.1016/j.ceramint.2017.07.053

41. K. Strecker, S. Ribeiro and M.-J. Hoffmann, Fracture Toughness Measurements of LPS-SiC: A Comparison of the Indentation Technique and the SEVNB Method, Mater. Res., 2005, 8(2), p 121-124. h ttps://doi.org/10.1590/s1516-14392005000200004

42. P. Arivalagan, G. Chandramohan, A. Kumar and N. Palaniappan, Studies on Dry Sliding Wear Behaviour of Hybrid Composites, Front. Automob. Mech. Eng., 2010 https://doi.org/10.1109/fame.2010.57147 96

43. T. Arunkumar, C. Jebasingh, P. Venkatachalam, J.B. Sajin and M. Anish, Abrasive Wear Behaviour of Plasma Sprayed $\mathrm{Al}_{2} \mathrm{O}_{3} / \mathrm{TiO}_{2}$ Coatings. Regular Issue, BEIESP, 2019, 9(2), p 5020-3. https://doi.org/ 10.35940/ijitee.b7604.129219

44. R. Hassan, A. Nisar, S. Ariharan, F. Alam, A. Kumar and K. Balani, Multi-functionality of Carbon Nanotubes Reinforced $3 \mathrm{~mol} \%$ Yttria Stabilized Zirconia Structural Biocomposites, Mater. Sci. Eng. A, 2017, 704, p 329-343. https://doi.org/10.1016/j.msea.2017.08.039

45. A. Nisar, S. Ariharan, T. Venkateswaran, N. Sreenivas and K. Balani, Oxidation Studies on TaC Based Ultra-High Temperature Ceramic Composites Under Plasma Arc Jet Exposure, Corros. Sci., 2016, 109, p 50-61. https://doi.org/10.1016/j.corsci.2016.03.013

46. N. Djourelov, Y. Aman, D. Sillou and P. Nédélec, Pore Closure in Spark Plasma Sintered Alumina Studied by Variable Energy Positrons, Eur. Phys. J. Appl. Phys., 2012, 57(2), p 20402. https://doi.org/10. 1051/epjap/2012110083

47. A. Datye, K.-H. Wu, G. Gomes, V. Monroy, H.-T. Lin, J. Vleugels et al., Synthesis, Microstructure and Mechanical Properties of Yttria Stabilized Zirconia (3YTZP)-Multi-Walled Nanotube (MWNTs) Nanocomposite by Direct in-Situ Growth of MWNTs on Zirconia Particles, Compos. Sci. Technol., 2010, 70(14), p 2086-2092. https://d oi.org/10.1016/j.compscitech.2010.08.005

48. S. Vasanthavel and S. Kannan, Structural Investigations on the Tetragonal to Cubic Phase Transformations in Zirconia Induced by Progressive Yttrium Additions, J. Phys. Chem. Solids, 2018, 112, p 100-105. https://doi.org/10.1016/j.jpcs.2017.09.010

49. J.P. Zhou, Q.M. Gong, K.Y. Yuan, J.J. Wu, Y. Fang Chen, C.S. Li et al., The Effects of Multiwalled Carbon Nanotubes on the Hot-Pressed 
3mol\% Yttria Stabilized Zirconia Ceramics, Mater. Sci. Eng. A, 2009, 520(1-2), p 153-7. https://doi.org/10.1016/j.msea.2009.05.014

50. J.G. Thakare, C. Pandey, R.S. Mulik and M.M. Mahapatra, Mechanical Property Evaluation of Carbon Nanotubes Reinforced Plasma Sprayed YSZ-Alumina Composite Coating, Ceram. Int., 2018, 44(6), p 6980 6989. https://doi.org/10.1016/j.ceramint.2018.01.131

51. N. Garmendia, I. Santacruz, R. Moreno and I. Obieta, Slip Casting of Nanozirconia/MWCNT Composites Using a Heterocoagulation Process, J. Eur. Ceram. Soc., 2009, 29(10), p 1939-1945. https://doi.org/ 10.1016/j.jeurceramsoc.2008.12.014

52. X. Wang, N.P. Padture and H. Tanaka, Contact-Damage-Resistant Ceramic/Single-Wall Carbon Nanotubes and Ceramic/Graphite Composites, Nat. Mater., 2004, 3(8), p 539-544. https://doi.org/10.1038/ nmat1161

53. N.P. Padture, Multifunctional Composites of Ceramics and SingleWalled Carbon Nanotubes, Adv. Mater., 2009, 21(17), p 1767-1770. h ttps://doi.org/10.1002/adma.200802270

54. S. Zhu, W.G. Fahrenholtz, G.E. Hilmas, S.C. Zhang, E.J. Yadlowsky and M.D. Keitz, Microwave Sintering of a ZrB2-B4C Particulate
Ceramic Composite, Compos. A Appl. Sci. Manuf., 2008, 39(3), p 449453. https://doi.org/10.1016/j.compositesa.2008.01.003

55. M.S. Asl, M.G. Kakroudi and S. Noori, Hardness and Toughness of Hot Pressed ZrB2-SiC Composites Consolidated Under Relatively Low Pressure, J. Alloys Compd., 2015, 619, p 481-487. https://doi.org/ 10.1016/j.jallcom.2014.09.006

56. S.I. Cha, K.T. Kim, K.H. Lee, C.B. Mo and S.H. Hong, Strengthening and Toughening of Carbon Nanotube Reinforced Alumina Nanocomposite Fabricated by Molecular Level Mixing Process, Scr. Mater, 2005, 53(7), p 793-797. https://doi.org/10.1016/j.scriptamat.2005.06. 011

57. N. Saini, C. Pandey, S. Thapliyal and D.K. Dwivedi, Mechanical Properties and Wear Behavior of $\mathrm{Zn}$ and MoS2 Reinforced Surface Composite Al- Si Alloys Using Friction Stir Processing, Silicon, 2018, 10(5), p 1979-1990. https://doi.org/10.1007/s12633-017-9710-2

Publisher's Note Springer Nature remains neutral with regard to jurisdictional claims in published maps and institutional affiliations. 